\title{
EXTRATO DE CHÁ VERDE (Camellia sinensis) PROMOVE AÇÃO ANTIMICROBIANA SOBRE Staphylococcus aureus
}

\author{
Leandro Wagner Figueira ${ }^{1}$ \\ Jonatas Rafael de Oliveira ${ }^{2}$ \\ Fábia Lugli Sper ${ }^{3}$ \\ Vanessa Marques Meccatti ${ }^{4}$ \\ Letícia de Oliveira ${ }^{5}$ \\ Luciane Dias de Oliveira ${ }^{6}$
}

Resumo: É de grande importância ampliar as pesquisas científicas com plantas medicinais sobre microorganismos. Foi verificado o efeito antimicrobiano do extrato de $C$. sinensis, sobre cultura planctônica e biofilme de S. aureus. Neste estudo foi verificada ação do extrato entre 50 a $0,09 \mathrm{mg} / \mathrm{mL}$ sobre cultura planctônica, para determinação da CIM e CBM. A ação do extrato sobre biofilme foi analisada pela exposição de $5 \mathrm{~min}$ ao produto vegetal a $200 \mathrm{mg} / \mathrm{mL}$. Foi utilizado o método de MTT para determinar a redução da viabilidade do biofilme. Nos grupos controles foram utilizadas clorexidina (+) e solução salina (), sendo $n=12$ /grupo. A redução do biofilme foi analisada por ANOVA e Tukey Test $(p \leq 0,05)$. Em cultura planctônica as concentrações avaliadas não foram efetivas, contudo, utilizando-se a concentração de 200 $\mathrm{mg} / \mathrm{mL}$ sobre o biofilme, foi verificada redução significativa. Com isso, concluiu-se que o extrato de chá verde demonstrou ação sobre biofilme de $S$. aureus provendo redução significativa em sua viabilidade.

Palavras-chave: Camellia sinensis, Staphylococcus aureus; Biofilme.

\footnotetext{
1 Universidade Estadual Julio Mesquita Filho/Unesp, Brasil. E-mail: leandrowf@live.com.

2 Universidade Estadual Julio Mesquita Filho/Unesp, Brasil. E-mail: jroliveira16@hotmail.com

3 Universidade Estadual Julio Mesquita Filho/Unesp, Brasil. E-mail: fabiafarma@hotmail.com

${ }^{4}$ Universidade Estadual Julio Mesquita Filho/Unesp, Brasil. E-mail: vanessa.tep@hotmail.com

${ }^{5}$ Universidade Estadual Julio Mesquita Filho/Unesp, Brasil. E-mail: leticia.4541@gmail.com

${ }^{6}$ Universidade Estadual Julio Mesquita Filho/Unesp, Brasil. E-mail: luciane@ict.unesp.br
} 